\title{
The impact of a community-led program promoting weight loss and healthy living in Aboriginal communities: the New South Wales Knockout Health Challenge
}

Erin Passmore ${ }^{1 *}$, Brooke Shepherd ${ }^{1}$, Andrew Milat ${ }^{1,2}$, Louise Maher ${ }^{1}$, Kiel Hennessey $^{3}$, Rachael Havrlant ${ }^{3}$, Michelle Maxwell ${ }^{1}$, Wendy Hodge ${ }^{4}$, Fiona Christian ${ }^{4}$, Justin Richards ${ }^{2,5}$ and Jo Mitchell ${ }^{1}$

\begin{abstract}
Background: Aboriginal people in Australia experience significant health burden from chronic disease. There has been limited research to identify effective healthy lifestyle programs to address risk factors for chronic disease among Aboriginal people.

Methods: The Knockout Health Challenge is a community-led healthy lifestyle program for Aboriginal communities across New South Wales, Australia. An evaluation of the 2013 Knockout Health Challenge was undertaken. Participants' self-reported physical activity and diet were measured at four time points - at the start and end of the Challenge (via paper form), and 5 and 9 months after the Challenge (via telephone survey). Participants' weight was measured objectively at the start and end of the Challenge, and self-reported (via telephone survey) 5 and 9 months after the Challenge. Changes in body composition, physical activity and diet between time points were analysed using linear mixed models. As part of the telephone survey participants were also asked to identify other impacts of the Challenge; these were analysed descriptively (quantitative items) and thematically (qualitative items).

Results: A total of 586 people registered in 22 teams to participate in the Challenge. The mean weight at the start was $98.54 \mathrm{~kg}$ (SD 22.4), and 94\% of participants were overweight or obese. Among participants who provided data at all four time points $(n=122)$, the mean weight loss from the start to the end of the Challenge was $2.3 \mathrm{~kg}(95 \% \mathrm{Cl}-3.0$ to -1 . $9, p<0.001)$, and from the start to 9 months after the Challenge was $2.3 \mathrm{~kg}(95 \% \mathrm{Cl}-3.3$ to $-1.3, p<0.001)$. Body mass index decreased by an average of $0.9 \mathrm{~kg} / \mathrm{m}^{2}(95 \% \mathrm{Cl}-1.0$ to $-0.7, p<0.001)$ from the start to the end of the Challenge, and $0.8 \mathrm{~kg} / \mathrm{m}^{2}(95 \% \mathrm{Cl}-1.2$ to $-0.4, p<0.001) 9$ months after. At the end of the Challenge, participants reported they were more physically active and had increased fruit and vegetable consumption compared with the start of the Challenge, and identified a range of other positive impacts.
\end{abstract}

Conclusions: The Challenge was effective in reducing weight and promoting healthy lifestyles among Aboriginal people across New South Wales, and has potential to contribute to closing the health gap between Aboriginal and non-Aboriginal people.

Keywords: Aboriginal, Obesity and overweight, Weight loss, Physical activity, Lifestyle program, Health promotion, Program evaluation

* Correspondence: passmoreerin@yahoo.com.au

${ }^{1}$ NSW Ministry of Health, North Sydney, NSW, Australia

Full list of author information is available at the end of the article 


\section{Background}

There are large disparities in the health status of Aboriginal people compared with non-Aboriginal people in Australia. Life expectancy is approximately 10.6 years lower for Aboriginal males and 9.5 years lower for Aboriginal females, compared with the non-Aboriginal population [1]. Chronic diseases account for two-thirds of this health gap: circulatory disease (24\% of the gap), endocrine, metabolic and nutritional disorders (21\%), cancer (12\%), and respiratory diseases (12\%) [1] . Aboriginal people also have a high prevalence of risk factors for chronic disease. For example, 66\% of Aboriginal adults are overweight or obese, and $97 \%$ of Aboriginal adults do not consume the recommended daily amounts of fruit and/or vegetables [2]. The causes of the health gap between Aboriginal and non-Aboriginal people are complex and include a range of social, cultural and environmental factors. Addressing health inequities and closing the life expectancy gap are key priorities for Aboriginal and non-Aboriginal organizations in Australia, including national and state governments [3].

There is strong evidence that lifestyle interventions addressing physical activity and diet are effective in promoting behavioural change [4], reducing chronic disease risk factors [5], and preventing chronic disease [6, 7] in the general population. A range of interventions to improve behavioural risk factors for chronic disease have been implemented in Aboriginal populations in Australia. Some programs have found short-term health improvements such as increased physical activity, improved diet and small decreases in weight, BMI and waist circumference [8-11]. For example, the Aboriginal and Torres Strait Islander Women's Fitness Program was a structured, 12week group program aimed at reducing waist circumference and improving metabolic health. The program was implemented in an urban area, and included twice-weekly exercise classes and four nutrition workshops. Compared with waitlisted controls, participants showed modest reductions in weight, BMI and blood pressure, which were maintained at three month follow-up [12]. Another program, a 12-week exercise intervention implemented with Aboriginal men in a regional area, resulted in significant reductions in BMI and waist circumference compared to controls. However, the small sample size (16 participants, 10 controls) is a significant limitation of this study [13].

Despite the growing evidence for effective communitybased lifestyle interventions for Aboriginal people, previous studies have been conducted in a single Aboriginal community, and to date there have been no evaluations of this type of program implemented on a larger scale in diverse Aboriginal communities. Since 2012, New South Wales (NSW) Health has partnered with NSW Rugby League to implement the NSW Knockout Health Challenge (the Challenge), a healthy lifestyle program for Aboriginal communities in NSW. To build the evidence base for large-scale interventions to promote healthy lifestyles in Aboriginal communities, an evaluation was undertaken to assess the impact of the 2013 Challenge on weight loss and health behaviour change among participants in a number of metropolitan, regional and rural Aboriginal communities in NSW.

\section{Methods}

\section{Intervention - the NSW Knockout Health Challenge}

The Challenge is a state-wide, community-led weight loss and healthy lifestyle program, in which teams compete to achieve the greatest weight loss over a 16-week period. The Challenge has been implemented annually since 2012, and is open to teams of Aboriginal people from across NSW. The aim of the Challenge is to promote weight loss and healthy living through increased physical activity and improved nutrition. In 2013, 22 teams from across NSW took part in the Challenge. The main components of the Challenge in 2013 were:

1. Establishment of the Knockout Challenge Town Committee and Team: Town Committees were established by communities interested in participating in the Challenge. Town Committees were made up of local volunteers from the health, local government, Aboriginal and community sectors, such as Aboriginal Community Controlled Health Services, Aboriginal Land Councils, Medicare Locals and Local Health Districts (LHDs). The Town Committees promoted the Challenge within their community, invited community members to join the Challenge team via targeted invitations and community-wide advertisement, and assisted Challenge teams to link with local health services and other community organisations. Challenge teams comprised 20 to 30 people and were led by a team manager whose role was to coordinate team activities.

2. Participation in the Challenge period: In 2013, the Challenge ran from March to June. During the Challenge, teams competed to achieve the greatest weight loss over a 16-week period. Teams developed their own healthy lifestyle activities to suit their local needs and resources. Although activities varied across the teams, teams typically participated in a diverse range of activities such as group fitness training, gym sessions, cooking workshops, weekly team meetings, monthly weigh-ins, visits to health care providers (e.g. general practitioner, Aboriginal Medical Service, nurse) to receive individual health advice, and dietitian consultations. Participants were also able to join the NSW Get Healthy Information and Coaching Service (a free telephone service staffed by qualified health coaches to support adults to make 
lifestyle changes) [14], and received motivational messages and support from Aboriginal National Rugby League players via Facebook. Challenge activities were supported by the state-wide implementation team, who provided training for team managers to develop programs of activities for their teams. Teams also received $\$ 1000$ start-up grants to support Challenge activities (e.g. to purchase exercise equipment), and were encouraged to link with local health organisations to receive ongoing local support. At the end of the Challenge, the three teams with the greatest weight loss percentage received a funding grant to further promote healthy lifestyles in their community; with grants of \$20,000, \$10,000 and $\$ 5,000$ for first, second and third place respectively.

3. Participation in the maintenance period: The 2013 Challenge was followed by a 12-week maintenance period (July to September 2013), in which teams were encouraged to stay together and maintain weight loss and lifestyle changes. During this period, Challenge teams had the opportunity to run a pedometer challenge where participants competed to achieve the greatest step count, and to compete in the Challenge Carnival, a sports day in which Challenge teams competed against each other in a range of sports and fitness activities.

\section{Evaluation methods}

The evaluation of the Challenge was completed between March 2013 and March 2014, and had three components: 1) quantitative assessment of participants' body composition and health behaviours, 2) quantitative and qualitative assessment of participants' experiences of the Challenge, and 3) qualitative interviews with team managers and the state-wide implementation team. This paper presents findings for components 1 and 2 .

Quantitative data on body composition and health behaviours All participants were invited to provide body composition and health behaviour data at four time points: at the start of the Challenge (March 2013, T1), the end of the Challenge (June 2013, T2), 5 months after completion of the Challenge (November 2013, T3) (selected to take place after a significant community event, the NSW Aboriginal Rugby League Knockout Carnival which was held in October), and 9 months after completion of the Challenge (March 2014, T4) (selected to coincide with the registration period for the 2014 Challenge).

Body composition At T1 and T2, participants' weight, height and waist circumference were objectively measured by a health professional; this was performed by their usual doctor or nurse. At T3, participants were invited (and systematically reminded) to attend a health professional to have their weight and waist circumference objectively measured, and provided a shopping voucher as reimbursement for their time. The intended evaluation design was to repeat the objective measurement of weight at T4, however this was not conducted due to a low response rate to the objective measures at T3.

Health behaviours At T1 and T2, participants completed a standard paper form collecting data on age, gender, chronic disease diagnoses, and self-reported health behaviours (fruit and vegetable consumption and physical activity levels). All self-reported measures were previously validated and are widely used to measure health behaviour $[15,16]$. At T3 and T4, the self-report measures were collected via computer assisted telephone interview (hereafter "telephone survey"), utilising the same questions as the T1 and T2 paper forms. In anticipation that the response rate to the $\mathrm{T} 3$ body composition measurement may be low, participants were also invited to self-report their current weight as part of the telephone survey at both T3 and T4 (participants were asked "What is your current weight?").

\section{Quantitative and qualitative assessment of participants' experiences of the Challenge}

In the T3 and T4 telephone surveys, participants were asked which Challenge activities they took part in, and perceived personal and community impacts of participating in the Challenge. For each of these questions, participants were read a list of potential options, and asked to identify which options applied to them (Yes/No response, multiple responses allowed). Participants were also asked an open-ended question about the personal and community impacts of the Challenge.

\section{Statistical analyses}

Quantitative data on body composition and health behaviours

The data were cleaned to remove duplicate records and outliers. Outliers were defined as over 30\% change in weight between any two consecutive time points; two outliers were removed - one at T3 and one at T4.

Baseline demographic characteristics of participants who provided data at both $\mathrm{T} 1$ and $\mathrm{T} 2$ were compared with participants who provided data at $\mathrm{T} 1$ only, using ttests for means and McNemar's chi-squared tests for proportions. Physical activity levels, fruit intake and vegetable intake were compared with Australian national guidelines [17, 18].

Two separate sets of analyses were completed to assess program impact. The first set of analyses comprised participants with data from all four time points. Body composition and health behaviours were compared for the following pairs of time points: T1-T2, T1-T3, and T1-T4. Changes in continuous variables between time points were 
analysed using linear mixed models. Included in the models were gender (as a fixed factor) and team (as a random factor). The second set of analyses repeated these procedures for participants who had data at each pair of time points (T1-T2, T1-T3, T1-T4).

In addition, to identify which components of the Challenge were associated with the greatest weight loss, the relationship between BMI change from $\mathrm{T} 1$ to $\mathrm{T} 2$ and participation in different components of the program was tested by multiple regression using forced entry. Factors included in the model were participation in various components of the Challenge (monthly weigh-ins, team meetings, accessing the Challenge Facebook page, visits to health care providers as part of the Challenge, dietitian consultations, contact with the Get Healthy Service during the Challenge, frequency of team training, and frequency of individual training). Demographic characteristics (age, gender, team, number of chronic illnesses, weight at $\mathrm{T} 1$, and whether the participant took part in the 2012 Challenge), were included as potential confounders.

All models satisfied the assumptions of lack of auto correlation, and linearity for metric predictors; variation inflation factor and tolerance statistics were within acceptable ranges. Statistical significance was assessed at $p=0.05$ in all analyses. All quantitative analysis was completed using SPSS V22.

\section{Quantitative and qualitative assessment of participants' experiences of the Challenge}

For quantitative data, the proportion of participants responding "Yes" to each response option was calculated. Responses to the open-ended question were transcribed, and analysed using a thematic analysis approach [19]. Analysis was conducted by one researcher, with review by a second researcher. The analysis of the openended telephone survey question involved identifying major themes of the impacts, whether these were negative or positive, and the type of impact (whether the changes were in knowledge, attitudes, behaviours, or health and social outcomes).

\section{Results}

\section{Participation in the Challenge and evaluation}

In 2013, 586 people registered for the Challenge in 22 teams. Teams were from 19 Aboriginal communities across NSW - 14 in regional or rural areas and 5 in metropolitan areas. The number of participants per team ranged from 22 to 30 (mean=26.6). The number of participants who provided data varied for each time point: T1 $(n=575,98.1 \%)$, T2 $(n=377,64.3 \%)$, T3 via telephone survey $(n=271,46.2 \%)$ and objective measurement of weight and waist circumference by a health professional $(n=76,13.0 \%)$, and T4 via telephone survey $(n=195$,
33.3\%). T3 and T4 weight data presented below are selfreported data from the T3 and T4 telephone surveys. Objective weight data collected at T3 were excluded from analysis due to the low response rate. After excluding the T3 objective weight data, twenty-one per-cent of participants $(n=122)$ provided data at all four time points (based on objective weight data at T1 and T2, and selfreport weight data at $\mathrm{T} 3$ and $\mathrm{T} 4$ ).

\section{Profile of Challenge participants}

The mean age of participants at the start of the Challenge was 39 years ( $\mathrm{SD}=13.6$ years, $n=575)$, ranging from 18 to 82 years. The majority of participants were women (72\%). Twenty-one per cent of participants in the 2013 Challenge had also taken part in the 2012 Challenge. At commencement the mean weight of participants was $98.5 \mathrm{~kg}(\mathrm{SD}=22.4 \mathrm{~kg}, n=575)$, mean BMI was $35.7 \mathrm{~kg} / \mathrm{m}^{2}$ $\left(\mathrm{SD}=7.8 \mathrm{~kg} / \mathrm{m}^{2}, n=575\right)$ and mean waist circumference was $113.3 \mathrm{~cm}(\mathrm{SD}=16.8 \mathrm{~cm})$ (Table 1$)$. Forty-one per cent of participants had a previous diagnosis of, and/or were being treated for, a health condition associated with body composition, physical activity and diet. Baseline characteristics between participants who provided data at T1 and T2 $(n=377)$ were similar to characteristics of participants who provided data at T1 only $(n=199)$; the only statistically significant difference was that participants who provided data at T1 only were more likely to consume the recommended amount of vegetables per day $(p=0.004)$ (Table 2).

\section{Participation in the Challenge}

In the T3 telephone survey $(n=271)$, participants were asked what types of activities they participated in during the Challenge, and how often. Participants were also asked whether they participated in the maintenance phase activities (pedometer challenge and Challenge Carnival). The activities participants most commonly took part in were monthly weigh-ins (87\%), team exercise sessions (86\%), individual exercise sessions (83\%), visits to health care providers (78\%) and team meetings (73\%). Participants reported they were involved in an average of 4 different weight loss or healthy lifestyle activities during the Challenge $(S D=1.5)$. Sixty-three per cent of participants reported participating in team exercise sessions at least once per week, and $73 \%$ reported participating individual exercise sessions at least once per week. In the maintenance period, $20 \%$ of participants took part in the pedometer challenge, and 30\% took part in the Challenge carnival.

\section{Impact on weight and health behaviour}

The results presented below are for participants who provided data for all four time points $(n=122)$ (Table 3$)$. There was a similar pattern of results for participants who provided data at each pair of time points (Table 1). 
Table 1 Summary of body composition and health behaviour for participants at each time point of the Knockout Health Challenge 2013

\begin{tabular}{|c|c|c|c|c|c|c|c|c|}
\hline \multirow[t]{2}{*}{ Measure } & \multicolumn{2}{|c|}{ Measure at start of Challenge (T1) } & \multicolumn{6}{|c|}{ Change at subsequent time points compared with $\mathrm{T} 1$} \\
\hline & $\mathrm{N}$ & $\mathrm{T} 1$ (SD) & $\mathrm{N}$ & T1-T2 (95\%Cl) & $\mathrm{N}$ & T1-T3 $(95 \%$ Cl) & $\mathrm{N}$ & T1-T4 (95\% Cl) \\
\hline Mean weight (kg) & 575 & $\begin{array}{l}98.5 \\
(22.4)\end{array}$ & 377 & $\begin{array}{l}-2.3^{*} \\
(-2.8,-1.8)\end{array}$ & 252 & $\begin{array}{l}-4.6^{*} \\
(-5.5,-3.6)\end{array}$ & 184 & $\begin{array}{l}-2.4^{*} \\
(-3.4,-1.3)\end{array}$ \\
\hline Mean BMI (kg/m²) & 575 & $\begin{array}{l}35.7 \\
(7.8)\end{array}$ & 377 & $\begin{array}{l}-0.8^{*} \\
(-1.0,-0.7)\end{array}$ & 252 & $\begin{array}{l}-1.6^{*} \\
(-2.0,-1.3)\end{array}$ & 185 & $\begin{array}{l}-0.9^{*} \\
(-1.3,-0.4)\end{array}$ \\
\hline Mean waist circumference $(\mathrm{cm})$ & 575 & $\begin{array}{l}113.3 \\
(16.8)\end{array}$ & 352 & $\begin{array}{l}-3.7^{*} \\
(-4.5,-3.0)\end{array}$ & & & & \\
\hline $\begin{array}{l}\text { Mean number days per week active for } \\
\text { 30mins or more }\end{array}$ & 545 & $\begin{array}{l}2.0 \\
(2.0)\end{array}$ & 312 & $\begin{array}{l}+0.8^{*} \\
(0.5,1.1)\end{array}$ & 266 & $\begin{array}{l}+0.6^{*} \\
(0.3,0.9)\end{array}$ & 192 & $\begin{array}{l}+0.6^{*} \\
(0.3,0.9)\end{array}$ \\
\hline$\%$ respondents sufficiently active & 545 & $\begin{array}{l}12.3 \\
(1.0)\end{array}$ & 312 & $\begin{array}{l}+6.5^{*} \\
(4.0,9.7)\end{array}$ & 266 & $\begin{array}{l}+7.9^{*} \\
(5,11.8)\end{array}$ & 192 & $\begin{array}{l}+6.3^{*} \\
(3.3,10.7)\end{array}$ \\
\hline Mean number serves of vegetables per day & 545 & $\begin{array}{l}2.3 \\
(1.5)\end{array}$ & 312 & $\begin{array}{l}+0.5^{*} \\
(0.4,0.7)\end{array}$ & 268 & $\begin{array}{l}+0.3^{*} \\
(0.1,0.5)\end{array}$ & 193 & $\begin{array}{l}+0.1 \\
(-0.1,0.4)\end{array}$ \\
\hline$\%$ eat recommended daily serves of vegetables & 545 & $\begin{array}{l}8.4 \\
(1.0)\end{array}$ & 312 & $\begin{array}{l}+7.0^{*} \\
(4.5,10.5)\end{array}$ & 268 & $\begin{array}{l}+3.7 \\
(1.8,6.8)\end{array}$ & 193 & $\begin{array}{l}-0.5 \\
(-2.1,0.0)\end{array}$ \\
\hline Mean number serves of fruit per day & 544 & $\begin{array}{l}1.5 \\
(1.2)\end{array}$ & 313 & $\begin{array}{l}+0.4^{*} \\
(0.2,0.6)\end{array}$ & 267 & $\begin{array}{l}+0.5^{*} \\
(0.4,0.7)\end{array}$ & 193 & $\begin{array}{l}+0.4^{*} \\
(0.2,0.6)\end{array}$ \\
\hline$\%$ eat recommended daily serves of fruit & 544 & $\begin{array}{l}47.4 \\
(2.0)\end{array}$ & 312 & $\begin{array}{l}+15.0^{*} \\
(11.2,19.5)\end{array}$ & 268 & $\begin{array}{l}+26.2^{*} \\
(21.0,31.9)\end{array}$ & 193 & $\begin{array}{l}+20.2^{*} \\
(14.8,26.6)\end{array}$ \\
\hline
\end{tabular}

${ }^{*} p<0.05$

\section{Body composition}

From T1 to T2, participants reduced their weight by an average of $2.3 \mathrm{~kg}(95 \% \mathrm{CI}-3.0$ to $-1.9, p<0.001)$, reduced their waist circumference by $3.7 \mathrm{~cm}(95 \% \mathrm{CI}-4.5$ to -3.0 , $p<0.001)$ and reduced their BMI by $0.9 \mathrm{~kg} / \mathrm{m}^{2}(95 \% \mathrm{CI}-1.0$ to $-0.7, P<0.001)$. Based on self-reported weight data from $\mathrm{T} 3$ and T4, these changes in body composition were

Table 2 Comparison of baseline characteristics of participants who provided data at T1 and T2 $(n=377)$ and those who provided data at T1 only $(n=199)$

\begin{tabular}{lll}
\hline & $\begin{array}{l}\text { Participants with } \\
\text { data at T1 and T2 } \\
N=377\end{array}$ & $\begin{array}{l}\text { Participants with } \\
\text { data at T1 but not T2 } \\
N=199\end{array}$ \\
\hline Mean age (years) & 40 years & 38 years \\
Female (\%) & 74.0 & 69.3 \\
Overweight (BMl>= & 94.7 & 93.5 \\
25.0kg/m ${ }^{2}$ (\%) & \\
Type 2 diabetes (\%) & 16.1 & 16.8 \\
High cholesterol (\%) & 15.9 & 14.4 \\
High blood pressure (\%) & 23.7 & 27.5 \\
Unstable asthma (\%) & 5.6 & 6.0 \\
Inadequate daily fruit & 50.9 & 47.2 \\
consumption (\%) & & $82.9^{*}$ \\
Inadequate daily vegetable & 91.0 & \\
consumption (\%) & & 25.1 \\
Daily smoker (\%) & 27.3 & \\
\hline * ${ }^{*}<0.05$ & &
\end{tabular}

maintained at T3 and T4. Overall, mean weight loss from $\mathrm{T} 1$ to $\mathrm{T} 4$ was $2.3 \mathrm{~kg}$ (95\%CI -3.3 to $-1.3, p<0.001)$.

\section{Physical activity}

From T1 to T2, the self-reported mean number of days participants were physically active for 30 minutes or more increased by 0.9 days per week (95\% CI 0.4 to 1.3 , $p<0.001$ ), from 2.0 to 2.9 days per week. At T4, the mean number of active days remained higher than at $\mathrm{T} 1$, but was not statistically significant. The proportion of participants meeting the Australian physical activity recommendations did not change significantly from $\mathrm{T} 1$ to $\mathrm{T} 2$, but increased significantly from T1 to T3 $(p<0.05)$, however this was not maintained at $\mathrm{T} 4$.

\section{Diet}

From T1 to T2, the self-reported mean number of servings of fruit per day increased significantly by 0.3 serves (95\%CI 0.1 to $0.6, p=0.016$ ) from 1.6 to 1.9 serves. This was maintained at T3 and T4. Similarly, the proportion of participants consuming the recommended daily serves of fruit increased significantly by $20.2 \%$ (95\%CI 13.1 to $28.9, p=0.002)$, from $49.5 \%$ to $69.7 \%$. This was maintained at $\mathrm{T} 3$ and $\mathrm{T} 4$.

From $\mathrm{T} 1$ to $\mathrm{T} 2$, the self-reported mean number of daily servings of vegetables increased significantly by 0.4 serves $(95 \%$ CI 0.1 to $0.7, p=0.007)$, however this was not maintained at T3 or T4. There was no significant change in the proportion of participants consuming the recommended daily serves of vegetables. 
Table 3 Summary of body composition and health behaviour for participants with data at all four time points of the Knockout Health Challenge 2013

\begin{tabular}{|c|c|c|c|c|c|}
\hline \multirow[t]{2}{*}{ Measure } & \multirow[t]{2}{*}{$\mathrm{N}$} & \multirow{2}{*}{$\begin{array}{l}\text { Measure at start of } \\
\text { Challenge } \mathrm{T1}(\mathrm{SD})\end{array}$} & \multicolumn{3}{|c|}{ Change at subsequent time points compared with $\mathrm{T} 1$} \\
\hline & & & $\mathrm{T} 1-\mathrm{T} 2(95 \% \mathrm{Cl})$ & T1-T3 (95\% Cl) & T1-T4 (95\% Cl) \\
\hline Mean weight (kg) & 122 & $\begin{array}{l}98.0 \\
(20.2)\end{array}$ & $\begin{array}{l}-2.3^{*} \\
(-3.0,-1.9)\end{array}$ & $\begin{array}{l}-4.6^{*} \\
(-5.5,-3.6)\end{array}$ & $\begin{array}{l}-2.3^{*} \\
(-3.3,-1.3)\end{array}$ \\
\hline Mean BMI $\left(\mathrm{kg} / \mathrm{m}^{2}\right)$ & 122 & $\begin{array}{l}35.8 \\
(6.7)\end{array}$ & $\begin{array}{l}-0.9^{*} \\
(-1.0,-0.7)\end{array}$ & $\begin{array}{l}-1.6^{*} \\
(-2.0,-1.3)\end{array}$ & $\begin{array}{l}-0.8^{*} \\
(-1.2,-0.4)\end{array}$ \\
\hline Mean waist circumference $(\mathrm{cm})$ & 352 & $\begin{array}{l}112.1 \\
(15.5)\end{array}$ & $\begin{array}{l}-3.7^{*} \\
(-4.5,-3.0)\end{array}$ & & \\
\hline Mean number days per week active for 30 mins or more & 109 & $\begin{array}{l}2.0 \\
(1.8)\end{array}$ & $\begin{array}{l}+0.9^{*} \\
(0.4,1.3)\end{array}$ & $\begin{array}{l}+0.7^{*} \\
(0.3,1.1)\end{array}$ & $\begin{array}{l}+0.4 \\
(-0.0,0.9)\end{array}$ \\
\hline$\%$ respondents sufficiently active & 109 & $\begin{array}{l}10.1 \\
(3.0)\end{array}$ & $\begin{array}{l}+6.4 \\
(2.6,12.8)\end{array}$ & $\begin{array}{l}+10.1^{*} \\
(5.1,17.3)\end{array}$ & $\begin{array}{l}+4.6 \\
(1.5,10.4)\end{array}$ \\
\hline Mean number serves of vegetables per day & 109 & $\begin{array}{l}2.6 \\
(1.4)\end{array}$ & $\begin{array}{l}+0.4^{*} \\
(0.1,0.7)\end{array}$ & $\begin{array}{l}+0.1 \\
(-0.2,0.4)\end{array}$ & $\begin{array}{l}-0.1 \\
(-0.4,0.2)\end{array}$ \\
\hline$\%$ eat recommended daily serves of vegetables & 109 & $\begin{array}{l}9.2 \\
(3.0)\end{array}$ & $\begin{array}{l}+6.4 \\
(2.6,12.8)\end{array}$ & $\begin{array}{l}+5.5 \\
(2,11.6)\end{array}$ & $\begin{array}{l}-2.8 \\
(-7.8,-0.6)\end{array}$ \\
\hline Mean number serves of fruit per day & 109 & $\begin{array}{l}1.6 \\
(1.0)\end{array}$ & $\begin{array}{l}+0.3^{*} \\
(0.1,0.6)\end{array}$ & $\begin{array}{l}+0.4^{*} \\
(0.1,0.6)\end{array}$ & $\begin{array}{l}+0.3^{*} \\
(0.1,0.6)\end{array}$ \\
\hline$\%$ eat recommended daily serves of fruit & 109 & $\begin{array}{l}49.5 \\
(5.0)\end{array}$ & $\begin{array}{l}+20.2^{*} \\
(13.1,28.9)\end{array}$ & $\begin{array}{l}+21.1^{*} \\
(13.9,30.0)\end{array}$ & $\begin{array}{l}+18.4^{*} \\
(11.6,26.9)\end{array}$ \\
\hline
\end{tabular}

${ }^{*} p<0.05$

\section{Factors associated with BMI reduction}

For all participants who provided data at T1 and T2 $(n=192)$, female participants $(p=0.008)$, those who engaged in more team training sessions $(p=0.025)$, and those who were heavier at the outset $(p=0.002)$ were more likely to reduce their BMI from T1 to T2 (Table 4).
Other impacts of the Challenge

In the T3 telephone interviews, participants were asked to describe the impacts of participating in the Challenge at personal and community level. Responses to the list of potential impacts, and illustrative quotes from responses to the open-ended question, are presented below.

Table 4 Participation and demographic factors associated with BMI change for participants from T1 to T2 of the Knockout Health Challenge 2013 ( $n=192)$

\begin{tabular}{|c|c|c|c|c|c|}
\hline Variable & B & $95 \% \mathrm{Cl}$ & SE B & $\beta$ & $p$ \\
\hline (Constant) & 1.115 & $(-0.638,2.867)$ & .888 & & .211 \\
\hline Participation in monthly weigh-ins & .694 & $(-0.333,1.722)$ & .521 & .105 & .184 \\
\hline Participation in team meetings & -.270 & $(-0.97,0.431)$ & .355 & -.058 & .448 \\
\hline Access to the Challenge Facebook page & -.224 & $(-0.76,0.312)$ & .272 & -.061 & .410 \\
\hline $\begin{array}{l}\text { Visits to health care providers (general practitioner, Aboriginal } \\
\text { medical service, nurse) as part of the Challenge }\end{array}$ & -.144 & $(-0.872,0.584)$ & .369 & -.030 & .697 \\
\hline Dietitian consultations & .223 & $(-0.323,0.768)$ & .276 & .059 & .421 \\
\hline Participation in the 2012 Challenge & -.447 & $(-1.069,0.175)$ & .315 & -.105 & .158 \\
\hline Contacted Get Healthy Service during the Challenge & .065 & $(-0.722,0.852)$ & .399 & .012 & .871 \\
\hline Frequency of team training & -.211 & $(-0.395,-0.027)$ & .093 & -.173 & $.025^{*}$ \\
\hline Frequency of individual training & .077 & $(-0.067,0.222)$ & .073 & .075 & .293 \\
\hline Number of chronic illnesses & .133 & $(-0.146,0.413)$ & .142 & .082 & .348 \\
\hline Weight at start of Challenge & -.022 & $(-0.036,-0.008)$ & .007 & -.237 & $.002^{*}$ \\
\hline Female & -.858 & $(-1.491,-0.225)$ & .321 & -.200 & $.008^{*}$ \\
\hline Age & -.020 & $(-0.045,0.004)$ & .012 & -.145 & .104 \\
\hline Team & -.025 & $(-0.069,0.018)$ & .022 & -.088 & .251 \\
\hline
\end{tabular}


Participants identified a range of benefits of participation in the Challenge. Ninety-one per cent of participants felt that participation in the Challenge had improved their physical health. Other benefits included improved knowledge of nutrition and physical activity (90\%), adopting a healthier diet (90\%), and increased physical activity (88\%).

I started eating healthier and thinking about what I am eating. Instead of grabbing a can of drink, I am going for water instead now.

Just a better awareness of diet and exercise. It's important. Many participants also reported improvements in wellbeing (76\%) and reduced anxiety and stress (76\%).

It helped me improve my self-esteem to get motivated to start exercising.

Better cholesterol, sugar dropped dramatically and generally my overall wellbeing mentally improved.

Participants also identified community benefits including improved awareness of healthy lifestyles in the community (88\%), and increased community pride and connectedness (87\%). Very few participants reported any adverse impacts from being involved in the Challenge, however some identified negative impacts such as community issues (8\%) and being frustrated when other team members dropped out of the Challenge (5\%). Many participants planned to take part in the next Challenge, with $44 \%$ of participants reporting they had re-enrolled for the 2014 Challenge.

\section{Discussion}

To our knowledge this is the first time a state-wide program targeting overweight and obesity among Aboriginal people has been successfully implemented and evaluated in a large number of communities. Our results show that Challenge participants lost weight and reduced their BMI, and these changes were maintained 9 months after the Challenge. Participants also increased their physical activity and mean daily fruit and vegetable intake during the Challenge; the increase in physical activity was maintained at 5 months, and fruit intake was maintained at 9 months, but vegetable intake was not maintained after the Challenge. Participants also identified a range of other benefits of participation, such as improved wellbeing.

At the start of the Challenge most participants were overweight, and only a small proportion of participants were meeting health recommendations for physical activity and diet. In addition, the proportion of participants who were overweight and physically inactive was substantially higher than the general NSW Aboriginal population [20]. The health profile of participants suggests the program successfully reached people at high risk of chronic health conditions.

The average weight loss observed in our study (mean weight loss of $2.3 \mathrm{~kg}$ from the start to the end of the Challenge) was greater than that reported in other similar intervention studies with Aboriginal people, which have reported weight loss of 1.3 to $1.7 \mathrm{~kg}[10,12$, 13]. A significant finding of our study is that participants' weight loss was maintained after the Challenge. Previous intervention studies with Aboriginal people have either not conducted long-term follow up [9, 10, 12, 13], or found that weight loss was not maintained [11]. In addition, research in the general population suggests participants in lifestyle interventions typically regain some weight in the following year [21]. Although participants' mean weight loss was modest, these changes are likely to have had a positive impact on participants' health. From the start of the Challenge to 9 months after, participants' mean weight improved from class 2 obese (which is associated with a severe risk of comorbidities [22]) to class 1 obese (moderate risk of comorbidities). There is evidence that even modest weight loss can result in positive metabolic changes for individuals [23].

A key strength of the Challenge model is that it was led by local Aboriginal communities and participants were local Aboriginal people. Community engagement in program design and implementation is considered a critical determinant of program effectiveness of healthy lifestyle programs for Aboriginal people [11, 24], and is widely acknowledged in the literature [25-27], by government [3] and by Aboriginal communities [28] as key to closing the gap in health outcomes between Aboriginal and non-Aboriginal people. Another strength of the Challenge model is the flexibility to adapt the program to suit local contexts. The program was devised to be accessible for participants across NSW, with a large majority of teams from regional or rural areas. This highlights the potential for the Challenge model to be adapted to have a broader reach to Aboriginal populations across NSW and Australia, while maintaining flexibility to address health issues that are local priorities. In addition, the finding that $21 \%$ of participants in the 2013 Challenge had also participated in the 2012 Challenge suggests the potential for the Challenge to become an annual event for some participants and communities.

The study has identified areas in which the Challenge model could be strengthened. Firstly, men were less likely than women to participate in the Challenge, and less likely than women to reduce their BMI during the Challenge. Low participation of men is not unique to the Challenge [29], with men's health seeking behaviours substantially lower than women's among both Aboriginal [30] and non-Aboriginal populations [31, 32]. Future research may seek to identify barriers to participation in healthy lifestyle interventions such as the Challenge, and whether these differ between Aboriginal men and women. Measures to increase male participation in future Challenges warrant further exploration, and could include strategies such as engaging male community 
leaders, and ensuring teams have access to both male and female health professionals [33]. Second, further efforts are required to support participants to increase vegetable intake. Evidence for effective interventions to increase individuals' vegetable intake in Aboriginal populations is limited [34], however interventions such as brief individual behavioural counselling [35] have been found to be effective in non-Aboriginal populations and could feasibly be incorporated in the Challenge model.

The evaluation has several limitations. First, weight was objectively measured at the start and end of the Challenge, but self-reported 5 and 9 months after the Challenge. Due to this change in measurement method, the weight data at 5 and 9 months must be interpreted with caution. Attempts were made to objectively measure weight at 5 months, however the low response rate meant that a more pragmatic approach had to be adopted. Given that changes in self-reported physical activity and diet were maintained at 5 and 9 months, it is reasonable to expect that participants would also continue to lose weight. Second, there was loss to follow-up over the course of the evaluation, with $46 \%$ of participants followed up at 5 months, and $33 \%$ at 9 months. However, the response rates are similar to other surveys of Aboriginal people, such as the response rate to the biomedical component of the combined National Aboriginal and Torres Strait Islander Health Measures Survey sample (40.4\%) [36]. Third, no data were collected on the sociodemographic characteristics of participants, and we are therefore unable to comment on the reach of the program across socioeconomic groups. A final limitation relates to the evaluation design. The evaluation used a pre-post design and did not include a control group. While experimental designs such as randomized controlled trials are preferred to observational designs in most circumstances, they are not always practicable in public health [37] - as was the case for this evaluation. It is increasingly argued that broader interpretations of research designs that place a greater emphasis on context, such as mixed-methods and quasi-experimental designs, are appropriate to answer public health research and evaluation questions [38-40]. Furthermore, evaluations of large scale state-wide interventions like the Challenge are rarely published in the literature [41], highlighting the importance of sharing these findings and lessons learned.

\section{Conclusions}

The Challenge was effective in reducing weight and promoting healthy lifestyles among Aboriginal people in NSW. The Challenge addresses key chronic disease risk factors such as weight and nutrition, and thereby has potential to contribute to closing the gap in health outcomes between Aboriginal and non-Aboriginal people.
This evaluation makes a substantial contribution to the evidence base for adaptable healthy lifestyle programs to reduce risk factors for chronic disease among Aboriginal people across Australia.

\section{Abbreviations \\ NSW: New South Wales; T1: Start of the Challenge; T2: End of the Challenge; T3: 5 months after completion of the Challenge; T4: 9 months after completion of the Challenge; The Challenge: Knockout Health Challenge}

\begin{abstract}
Acknowledgements
We would like to thank the communities and individuals who participated in the NSW Knockout Health Challenge and the evaluation. The Challenge was funded by the NSW Ministry of Health, and implemented by the NSW Agency for Clinical Innovation in partnership with the NSW Ministry of Health, NSW Office of Preventive Health and NSW Rugby League. The NSW Ministry of Health contracted ARTD Consultants to undertake data collection and analysis for this evaluation. The authors wish to thank all these agencies for their valuable partnership in the evaluation.
\end{abstract}

Funding

The implementation and evaluation of the Knockout Health Challenge was funded by the NSW Ministry of Health.

\section{Availability of data and materials}

The dataset supporting the conclusions of this article is not included within the article, as participant consent and ethics approval pertained only to the use of data for the purpose of evaluation of the Knockout Health Challenge, and in line with NSW Aboriginal Health Information Guidelines which require that Aboriginal people be engaged in the analysis, interpretation and reporting of Aboriginal health and health-related information. All other study materials are available from the authors on request.

\section{Authors' contributions}

EP participated in study design, coordinated the evaluation and helped draft the manuscript. BS drafted the manuscript. AM and LM participated in study design and helped coordinate the evaluation. $\mathrm{KH}, \mathrm{RH}, \mathrm{MM}$ and JM led the implementation of the Challenge and participated in study design. WH and FC participated in study design, and conducted the data collection and analysis. JR advised on the analytical approach and final program reporting. All authors contributed to the interpretation of the study findings and development of the manuscript, and read and approved the final manuscript.

Ethics approval and consent to participate

Ethics approval for this study was given by the Aboriginal Health and Medical Research Council Ethics Committee (Reference 937/13). All participants provided informed consent to participate in the evaluation.

Consent for publication

Not applicable

Competing interests

The authors have no competing interests to declare.

\section{Publisher's Note}

Springer Nature remains neutral with regard to jurisdictional claims in published maps and institutional affiliations.

\section{Author details}

${ }^{1}$ NSW Ministry of Health, North Sydney, NSW, Australia. ${ }^{2}$ Sydney School of Public Health, University of Sydney, Sydney, NSW, Australia. ${ }^{3}$ NSW Agency for Clinical Innovation, Chatswood, NSW, Australia. ${ }^{4}$ ARTD Consultants, Level 4/ 352 Kent Street, Sydney, NSW, Australia. ${ }^{5}$ Charles Perkins Centre, University of Sydney, Sydney, NSW, Australia. 
Received: 7 June 2016 Accepted: 28 November 2017 Published online: 13 December 2017

\section{References}

1. Australian Institute of Health and Welfare. Mortality and life expectancy of Indigenous Australians: 2008 to 2012. Canberra: AlHW; 2014.

2. Australian Institute of Health and Welfare. The health and welfare of Australia's Aboriginal and Torres Strait Islander peoples 2015. Canberra: AlHW. p. 2015

3. Council of Australian Governments. National Partnership Agreement on Closing the Gap in Indigenous Health Outcomes. Canberra: Council of Australian Governments; 2008.

4. Sargent GM, Forrest LE, Parker RM. Nurse delivered lifestyle interventions in primary health care to treat chronic disease risk factors associated with obesity: a systematic review. Obes Rev. 2012;13(12):1148-71.

5. Hassan Y, Head V, Jacob D, Bachmann MO, Diu S, Ford J. Lifestyle interventions for weight loss in adults with severe obesity: a systematic review. Clin Obes. 2016;6(6):395-403.

6. Thoma C, Day CP, Trenell MI. Lifestyle interventions for the treatment of non-alcoholic fatty liver disease in adults: a systematic review. J Hepatol. 2012;56(1):255-66

7. Schellenberg ES, Dryden DM, Vandermeer B, Ha C, Korownyk C. Lifestyle interventions for patients with and at risk for type 2 diabetes: a systematic review and meta-analysis. Ann Intern Med. 2013;159(8):543-51.

8. Pressick EL, Gray MA, Cole RL, Burkett BJ. A systematic review on research into the effectiveness of group-based sport and exercise programs designed for Indigenous adults. J Sci Med Sport. 2015;19(9):726-32.

9. Chan LC, Ware R, Kesting J, Marczak M, Good D, Shaw JT. Short term efficacy of a lifestyle intervention programme on cardiovascular health outcome in overweight Indigenous Australians with and without type 2 diabetes mellitus: The healthy lifestyle programme (HELP). Diabetes Res Clin Pr. 2007;75(1):65-71.

10. Dimer L, Dowling T, Jones J, Cheetham C, Thomas T, Smith J, McManus A, Maiorana AJ. Build it and they will come: outcomes from a successful cardiac rehabilitation program at an Aboriginal Medical Service. Aust Health Rev. 2013;37(1):79-82.

11. Rowley KG, Daniel M, Skinner K, Skinner M, White GA, O'Dea K. Effectiveness of a community-directed 'healthy lifestyle' program in a remote Australian Aboriginal community. Aust NZ J Pub Health. 2000:24(2):136-44.

12. Canuto KJ, Cargo M, Li M, D'Onise K, Esterman A, McDermott R. Pragmatic randomised trial of a 12-week exercise and nutrition program for Aboriginal and Torres Strait Islander women: clinical results immediate post and 3 months follow-up. BMC Public Health. 2012;12:933. doi:10.1186/1471-2458-12-933.

13. Mendham AE, Duffield R, Marino F, Coutts AJ. A 12-week sports-based exercise programme for inactive Indigenous Australian men improved clinical risk factors associated with type 2 diabetes mellitus. J Sci Med Sport. 2015;8(4):438-43.

14. NSW Health. Get Healthy Information and Coaching Service. http://www. gethealthynsw.com.au/. Accessed 23 December 2016.

15. Milton K, Bull FC, Bauman A. Reliability and validity testing of a single-item physical activity measure. Br J Sports Med. 2010; doi:10.1136/bjsm.2009.068395.

16. Dal Grande E, Fullerton S, Taylor AW. Reliability of self-reported health risk factors and chronic conditions questions collected using the telephone in South Australia, Australia. BMC medical research methodology. 2012;12(1):108.

17. National Health and Medical Research Council. Australian Dietary Guidelines. Canberra: National Health and Medical Research Council; 2013.

18. Australian Government Department of Health. Australia's physical activity and sedentary behaviour guidelines. http://www.health.gov.au/internet/ main/publishing.nsf/Content/health-pubhlth-strateg-phys-act-guidelines/ \$File/FS-Adults-18-64-Years.PDF. Accessed December 232016.

19. Boyatzis RE. Transforming qualitative information: thematic analysis and code development. Thousand Oaks: California Sage Publications; 1998.

20. Australian Bureau of Statistics. National Aboriginal and Torres Strait Islander Health Survey 2012-13. Canberra: Australian Bureau of Statistics; 2014.

21. Barte JC, Ter Bogt NC, Bogers RP, Teixeira PJ, Blissmer B, Mori TA, Bemelmans WJ. Maintenance of weight loss after lifestyle interventions for overweight and obesity, a systematic review. Obes Rev. 2010;11(12):899-906.

22. World Health Organization. Global Database on Body Mass Index. 2004. http://apps.who.int/bmi/index.jsp?introPage=intro_3.html. Accessed 23 December 2016
23. Wing RR, Lang W, Wadden TA, Safford M, Knowler WC, Bertoni AG, Hill JO, Brancati FL, Peters A, Wagenknecht L. Look AHEAD Research Group. Benefits of modest weight loss in improving cardiovascular risk factors in overweight and obese individuals with type 2 diabetes. Diabetes care. 2011;34(7):1481-6.

24. Schembri L, Curran J, Collins L, Pelinovskaia M, Bell H, Richardson C, Palermo $C$. The effect of nutrition education on nutrition-related health outcomes of Aboriginal and Torres Strait Islander people: a systematic review. Aust NZ J Public Health. 2015;40(Suppl. 1):S42-7.

25. Mackean T, Adams M, Goold S, Bourke C, Calma T. Partnerships in action: addressing the health challenge for Aboriginal and Torres Strait Islander peoples. Med J Aust. 2008;188(10):554-5.

26. Jamieson LM, Paradies YC, Eades S, Chong A, Maple-Brown L, Morris P, Brown A. Ten principles relevant to health research among Indigenous Australian populations. Med J Aust. 2012;197(1):16-8.

27. Wenitong M, Mokak R, Councillor $H$, Thiele DD, Calma T. Rising to the health challenge for Aboriginal and Torres Strait Islander peoples: what will it take? Med J Aust. 2007;186(10):491-2.

28. Aboriginal Health and Medical Research Council of NSW. Strategic Plan 2011-2014. Sydney: Aboriginal Health and Medical Research Council; 2011. http://www.ahmrc.org.au/media/resources/ah-mrc-constitution-strategicplan/282-ah-mrc-of-nsw-strategic-plan-2011-2014/file.html. Accessed 6 Dec 2017.

29. O'Hara BJ, Phongsavan P, Venugopal K, Bauman AE. Characteristics of participants in Australia's Get Healthy telephone-based lifestyle information and coaching service: reaching disadvantaged communities and those most at need. Health Educ Res. 2011;26(6):1097-106.

30. Wenitong M, Adams M, Holden CA. Engaging Aboriginal and Torres Strait Islander men in primary care settings. Med J Aust. 2014;200(11):632-3.

31. World Health Organization. Engaging men and boys in changing genderbased inequity in health: Evidence from programme interventions. Geneva: World Health Organization. 2007. http://www.who.int/gender/documents/ Engaging_men_boys.pdf. Accessed 6 Dec 2017.

32. Malcher G. Engaging men in health care. Aust Fam Physician. 2009;38(3):92-5.

33. Anderson C, Seff $L R$, Batra A, Bhatt C, Palmer RC. Recruiting and Engaging Older Men in Evidence-Based Health Promotion Programs: Perspectives on Barriers and Strategies. J Aging Research. 2016; doi:10.1155/2016/8981435

34. Clifford A, Pulver LJ, Richmond R, Shakeshaft A, Ivers R. Smoking, nutrition, alcohol and physical activity interventions targeting Indigenous Australians: rigorous evaluations and new directions needed. Aust N Z J Public Health. 2011;35(1):38-46.

35. Steptoe A, Perkins-Porras L, McKay C, Rink E, Hilton S, Cappuccio FP. Behavioural counselling to increase consumption of fruit and vegetables in low income adults: randomised trial. BMJ. 2003;326(7394):855-61.

36. Australian Bureau of Statistics. 2014. 4727.0.55.003 Australian Aboriginal and Torres Strait Islander Health Survey: Biomedical Results, 2012-13. http://www.ausstats.abs.gov.au/Ausstats/subscriber.nsf/0/655722F5D777 ACA4CA257D4E00170CEC/\$File/4727.0.55.003\%20publication.pdf. Accessed 6 Dec 2017

37. Medical Research Council. Developing and evaluating complex interventions: new guidance. 2008. https://www.mrc.ac.uk/documents/pdf/ complex-interventions-guidance/ .Accessed 23 December 2016.

38. Greenhalgh T, Humphrey C, Hughes J, Macfarlane F, Butler C, Pawson R. How do you modernize a health service? A realist evaluation of whole scale transformation in London. Milbank Q. 2009;87(2):391-416.

39. Sanson-Fisher RW, D'Este CA, Carey ML, Noble N, Paul CL. Evaluation of Systems-Oriented Public Health Interventions: Alternative Research Designs. Ann Rev Pub Health. 2014:35:9-27.

40. Sanson-Fisher RW, Bonevski B, Green LW, D'Este C. Limitations of the randomized controlled trial in evaluating population-based health interventions. Am J Prev Med. 2007;33(2):55-161.

41. Milat AJ, Bauman AE, Redman S, Curac N. Public health research outputs from efficacy to dissemination: a bibliometric analysis. BMC Public Health. 2011:11:934. doi:10.1186/1471-2458-11-934. 